
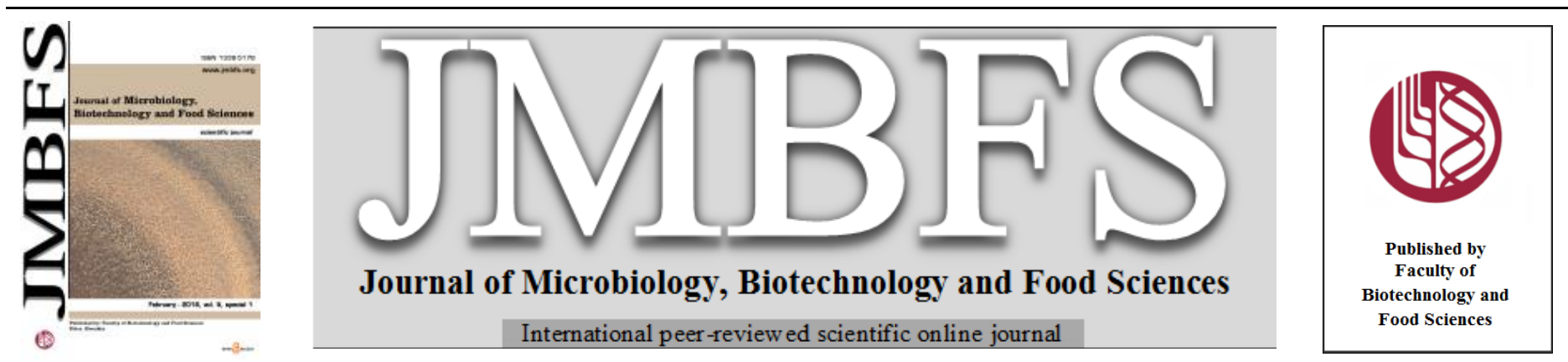

\title{
ANTIBACTERIAL ACTIVITY OF DROSERA ROTUNDIFOLIA L. AGAINST GRAM-POSITIVE AND GRAM- NEGATIVE BACTERIA
}

\author{
Dominika Ďurechová* ${ }^{1}$, Miroslava Kačániová ${ }^{1}$, Margarita Terentjeva ${ }^{2}$, Jana Petrová ${ }^{1}$, Lukáš Hleba ${ }^{1}$, Iwona Kata ${ }^{3}$ \\ Address(es): \\ ${ }^{1}$ Slovak University of Agriculture, Faculty of Biotechnology and Food Sciences, Department of Microbiology, Tr. A. Hlinku 2, 94976 Nitra, Slovak Republic. \\ ${ }^{2}$ Institute of Food and Environmental Hygiene, Faculty of Veterinary Medicine, Latvia University of Agriculture, K. Helmaņa iela 8, LV-004, Jelgava, Latvia. \\ ${ }^{3}$ Faculty of Biology and Agriculture, University of Rzeszow, Zelwerowicza St. 4, 35-601 Rzeszow, Poland.
}

*Corresponding author: dominika.durechova@gmail.com

doi: 10.15414/jmbfs.2016.5.special1.20-22

\section{ARTICLE INFO}

Received 23. 12. 2015

Revised 20.1.2016

Accepted 24. 1. 2016

Published 8. 2. 2016

Regular article open $\partial_{\text {ACCESS }}$

\begin{abstract}
The medicinal use of genus Drosera, as an important antitussive for different respiratory diseases, has been known for centuries. Many of extracts from carnivorous plants exhibit various antibacterial and antifungal activities. Naphthoquinones containing extracts from Drosera have antiviral, antibacterial, antifungal, aphrodisiac, antispasmodic, antileprosy, antisclerotic and anticancer properties. The aim of the present study was to detect antibacterial activity of Drosera rotundifolia against Gram-positive and Gram-negative bacteria by the testing of MIC. For the study six strains of microorganisms were selected and there were Gram-positive bacteria -Bacillus thuringiensis (CCM 19T), Clostridium perfringens (CCM 4991), and Listeria monocytogenes (CCM 4699), as well as and Gramnegative bacteria - Escherichia coli (CCM 3988), Salmonella enterica subsp. enterica (CCM 3807) and Yersinia enterocolitica (CCM 5671). Plant extracts were isolated from three plants of Drosera rotundifolia L. (S1, S2 and S3) in different time range. The most effective extract with MIC50 value of $17.07 \mu \mathrm{g} \cdot \mathrm{ml}^{-1}$ was S3, while forMIC90 of $19.05 \mu \mathrm{g} . \mathrm{ml}^{-1}$ were extracts S2 and S3 exhibiting antimicrobial activity against Bacillus thuringiensis, Clostridium perfringens and Listeria monocytogenes. Extracts S1, S2 showed MIC50 value $25.53 \mu \mathrm{g} \cdot \mathrm{ml}^{-1}$ for all the microorganism tested, but S3 extract revealed the same antimicrobial activity against Yersinia enterocolitica, Salmonella enterica subsp. enterica and Escherichia coli. Extract S1 has MIC90 value of $27.14 \mu \mathrm{g} \cdot \mathrm{ml}^{-1}$ against all the microorganism tested, but S2 and S3 shared the same MIC90 for Yersinia enterocolitica, Salmonella enterica subsp. enterica and Escherichia coli.
\end{abstract}

Keywords: Drosera rotundifolia, carnivory, minimal inhibitory concentration (MIC), antimicrobial activity

\section{INTRODUCTION}

Plants have several ways of taking up nutrients; among them one of the highly specialized way is carnivory. The more than 600 known species of carnivorous plants constitute a very diverse group, often very distantly related species originating from different systematic orders and families. The common feature of those plans is the ability to hunt and consume animals and this unites in this group the species from various climatic and geographical areas differing morphologically and ecologically (Studnička, 2006). Carnivorous plants capture and utilize nutrients of prey, which consists mostly from insects (Darwin, 1875; Juniper et al., 1989). These plants occur in areas such as wetlands, alpine mountain peaks, vulcanic platform. They are characterized by growth on the sunny areas, the water-rich sites, but also are able to grow in medium poor of nutrient (Jurgens et al., 2012). Plants have elaborated adaptation to prey on and use the nutrients of victim with specialized leaves, the secretion of sticky substances, digestive enzymes and nectar to attract a prey (Thorén et al., 2003) The ability of plants to catch insects was firstly observed in 1759 at Venus flytrap (Dionaea muscipula) by Arthur Dobbs (Studnička, 2006). A more detailed description of carnivory plants described by Charles Darwin (1875) and still represents the fundamental work on insectivorous plants (Darwin, 1875).

The genus Drosera represents a good model of plant evolution and functional adaptation. Importantly, extracts from numerous species of Drosera have been traditionally used for various medicinal purposes (Šamaj et al., 1999). The Drosera genus is a natural source of pharmacologically important secondary compounds used as substrates in the production of pharmaceuticals. The most important are naphthoquinones, especially plumbagin,7-methyljuglone and flavonoids (Banasiuk et al., 2012). Particularly, naphthoquinones are thought to be responsible for therapeutic effects in respiratory diseases including bronchial infections and tuberculosis. The naphthoquinones, and specially plumbagin, also inhibits a development of parasitic nematodes and insects (Collantes et al., 2014). The extracts from Drosera which contain naphtoquinones share medical and other valuable properties and the antiviral, antibacterial, antifungal, aphrodisiac, antispasmodic, antileprosy, antisclerotic and anticancer properties are recognized (Juniper et al., 1989; Šamaj et al., 1999).

The present study was focused on Drosera rotundifolia of genus Drosera, which might be a pharmacologically important plant for its antimicrobial activity. The aim of this study was to evaluate the antibacterial activity of Drosera plant extracts by the detection of the minimal inhibitory concentration (MIC). Antimicrobial activity of six bacteria: Gram-positive _Bacillus thuringiensis, Clostridium perfringens, Listeria monocytogenes and Gram-negative bacteria Yersinia enterocolitica, Salmonella enterica subsp. enterica and Escherichia coli were evaluated

\section{MATERIALS AND METHODS}

\section{Plant material}

Plants of Drosera rotundifolia L. were cultivated in vitro on basal MS medium (DUCHEFA) supplemented with $2 \%(\mathrm{w} / \mathrm{v})$ of sucrose and $0.8 \%(\mathrm{w} / \mathrm{v})$ of agar (Bobák et al., 1995). The plantlets were cultivated at $20 \pm 2{ }^{\circ} \mathrm{C}$ with a day length of $16 \mathrm{~h}$ under $50 \mu \mathrm{Em}^{-2} \mathrm{~s}^{-1}$ light intensity. Plant extracts were isolated from three plants of Drosera rotundifolia L. in different time range.

\section{Microorganisms}

In this study the six bacteria species representing different strains were tested. Among tested were Gram-positive - Bacillus thuringiensis CCM 19T, Clostridium perfringens CCM 4991, Listeria monocytogenes CCM 4699 and Gram-negative bacteria - Escherichia coli CCM 3988, Salmonella enterica subsp. enterica CCM 3807 and Yersinia enterocolitica CCM 5671. All tested strains were collected from the Czech Collection of Microorganisms (Brno, 
Czech republic). The bacteria were cultured in the nutrient broth for obtaining of bacterial suspension (Imuna, Slovakia) at $37^{\circ} \mathrm{C}$.

\section{Preparation of plant extracts}

Whole plants of Drosera rotundifolia L. were dried and crushed. Weights of plant before and after drying are showed in Table 1. Crushed plants were dissolved in $96 \%$ ethanol (Sigma, Germany) and stored at room temperature in the dark for two weeks to prevent the degradation of active components. Then the ethanolic plant extracts were subjected to evaporation under reduced pressure at $40{ }^{\circ} \mathrm{C}$ in order to remove the ethanol (Stuart RE300DB rotary evaporator, Bibby scientific limited, UK, vacuum pump KNF N838.1.2KT.45.18, KNF, Germany). For the antimicrobial assay, the crude plant extracts were dissolved in dimethyl sulfoxide (DMSO) (Penta, Czech Republic) to equal $102.4 \mathrm{mg} / \mathrm{mL}$ as stock solution, while for chemical analysis ethanol was used as solvent.

Analysis of the essential oils was carried out with Hewlett-Packard 5890/5970 GC-MSD system.

Table1 Information about plants extracts

\begin{tabular}{lcccc}
\hline Sample & $\begin{array}{c}\text { Weight } \\
\text { before } \\
\text { drying }\end{array}$ & $\begin{array}{c}\text { Weight after } \\
\text { drying }\end{array}$ & $\begin{array}{c}\text { Sample in } \\
\text { DMSO }\end{array}$ & $\begin{array}{c}\text { Chemical } \\
\text { composition }\end{array}$ \\
\hline S1 & 8.82g & $0.74 \mathrm{~g}$ & $570 \mu \mathrm{l}$ & $\begin{array}{c}\text { gallic acid } 0.5 \%, \\
\text { hyperoside } 0.4 \%, \\
\text { droseroside } 1 \%, \\
\text { tanine } 0.6 \% \\
\text { gallic acid } 1.7 \%, \\
\text { hyperoside } 1.2 \%, \\
\text { droseroside } 2.3 \%, \\
\text { tanine } 1.6 \% \\
\text { S2 }\end{array}$ 11.42g \\
& $0.61 \mathrm{~g}$ & $690 \mu 1$ & $\begin{array}{c}\text { gallic acid } 1.2 \%, \\
\text { hyperoside } 0.6 \%, \\
\text { droseroside } 1.3 \%, \\
\text { tanine } 0.2 \%\end{array}$ \\
\hline
\end{tabular}

\section{Microbroth dilution method}

The minimal inhibitory concentrations (MICs) in vitro of the compounds were determined by the microbroth dilution method according to the Clinical and Laboratory Standards Institute recommendation (CLSI, 2009) in Mueller Hinton broth (Biolife, Italy).

The test samples were dissolved in dimethyl sulphoxide (DMSO) and the stock solutions of the serial two-fold dilutions with the final concentrations ranging between 0.5-512 $\mu \mathrm{g} \cdot \mathrm{ml}^{-1}$ were obtained. After that the each well was inoculated with a $100 \mu 1$ volume of working microbial suspension at the final density of 0.5 McFarland. Bacterial strains were grown at $37 \pm 0.5^{\circ} \mathrm{C}$ for $20-24 \mathrm{~h}$. Additionally wells for positive control (wells without bacteria), inoculum viability (no extract added) and the DMSO as negative control were reserved in each plate.

The inhibition of microbial growth was evaluated by measuring the well absorbance at $450 \mathrm{~nm}$ in an absorbance microplate reader Biotek EL808 with shaker (Biotek Instruments, USA). The absorbance in 96 microwell plates was measured before and after experiment. Differences between both measurements prior and after incubation were evaluated as a growth.

\section{Statistical analysis}

Measurement error was established for 0.05 values of absorbance. Differences in absorbance between the measurements before and after the analysis were expressed as a set of binary values.

These values were assigned to exact concentrations. The following formula was created for this specific experiment: value 1 (inhibitory effect) was assigned to absorbance values lower than 0.05 , while value 0 (no effect or stimulant effect) was assigned to absorbance values higher than 0.05 . For this statistical evaluation the probit analysis in Statgraphics software was used (Kačániová et al., 2015).

\section{RESULTS AND DISCUSSION}

The Drosera genus, native to Australia and New Zealand, includes multiple carnivorous species which possess substantial medicinal potential. Medicinal use of Drosera is convenient due to the simplicity of its cultivation in vitro. Drosera extracts owe their antimicrobial properties to secondary metabolites. Naphthoquinones, mainly plumbagin are the main active compounds produced by D. binata tissues. The plants are also a source of flavonoids, ellagic acid and their glycoside and methyl derivatives (Zehl $\boldsymbol{e t}$ al., 2011). It is crucial that plant extracts, unlike antibiotics, do not contribute to the emergence of resistant bacterial strains when used as antibacterial agents. Various studies showed interactions between several secondary metabolites found in plant extracts, which allowed herbal drugs to be used in lower doses of active components (Krolicka et al., 2008).
The antimicrobial activity of Drosera rotundifolia L. was determined previously by the disc diffusion assay of extracts. Ethanolic extracts of D. rotundifolia showed an antimicrobial effect against Yersinia enterocolitica, Bacillus thurigensis and Salmonela enterica (Kačániová et al., 2014). Carnivorous plant D. rotundifolia assumes to be a good source of compounds which posses antimicrobial effect against different Gram-negative and Gram-positive pathogenic bacteria. In this study the minimal inhibitory concentrations (MICs) of the compounds of individual extracts from three plants of $D$. rotundifolia by the microbroth dilution assay for a quantitative determination were evaluated.

Minimum inhibitory concentrations are considered as a great method for determining the susceptibility of organisms to antimicrobials and are therefore used to judge the performance of all other methods of susceptibility testing and MIC is defined as the lowest concentration of a ,,drug, that will inhibit the visible growth of an organisms after incubation (Andrews, 2001).

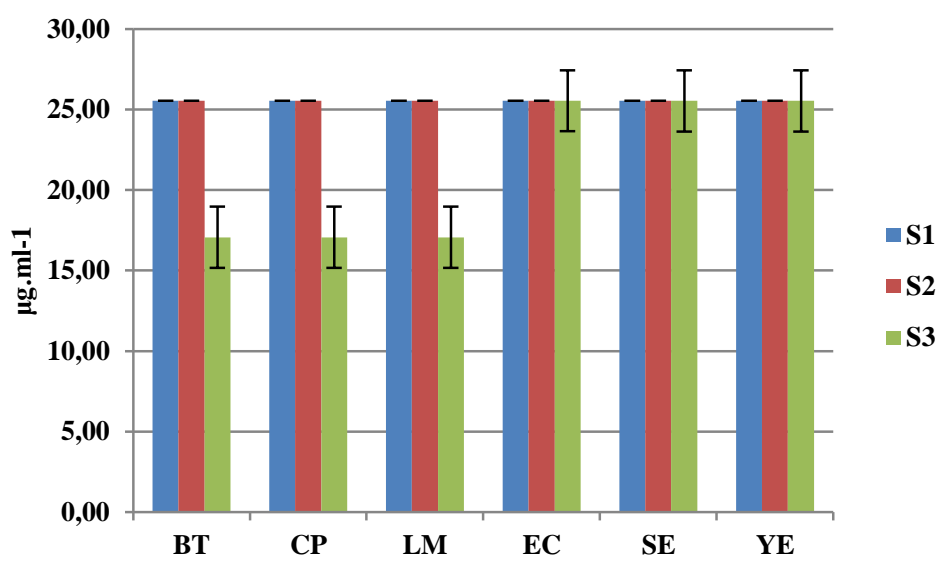

Figure 1 Antimicrobial activity MIC 50 of Drosera rotundifolia L.

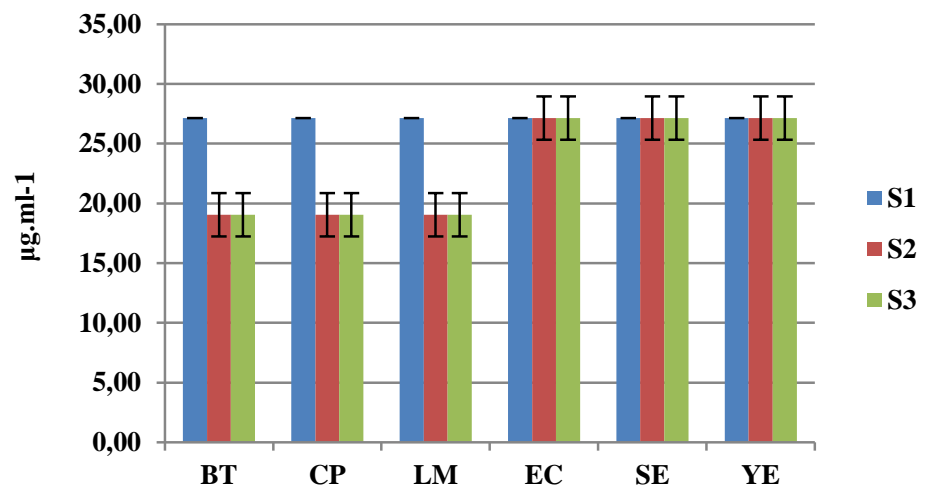

Figure 2 Antimicrobial activity MIC 90 of Drosera rotundifolia L extracts (S1, $\mathrm{S} 2$ and $\mathrm{S} 3$ ) extracts (S1, S2 and S3)

BT - Bacillus thuringiensis CCM 19T, CP - Clostridium perfringens CCM 4991, LM - Listeria monocytogenes CCM 4699, EC - Escherichia coli CCM 3988, SE - Salmonella enterica subsp. enterica CCM 3807, YE - Yersinia enterocolitica CCM 5671.

The antimicrobial activity $\left(\mu \mathrm{g} \cdot \mathrm{ml}^{-1}\right)$ of three extracts of Drosera rotundifolia L. against various strains of Gram-positive and Gram-negative bacteria are summarized in Figures 1 and 2. The most effective extract with MIC50 value of $17.07 \mu \mathrm{g} \cdot \mathrm{ml}^{-1}$ was extract S3 and with MIC90 of $19.05 \mu \mathrm{g} \cdot \mathrm{ml}^{-1}$ were extracts S2 and S3. The extract S3 with MIC50 was the most active against Bacillus thuringiensis, Clostridium perfringens and Listeria monocytogenes, while the extracts S2 and S3 were the most effective against Bacillus thuringiensis, Clostridium perfringens and Listeria monocytogenes at MIC90. This results correspond with the results of the previous study, where the individual differences between the extracts obtained were observed and extract DR3 showed the best antimicrobial activity against $B$. thuringiensis (Kačániová et al., 2014). Against Yersinia enterocolitica, Salmonella enteric subsp. enterica and Escherichia coli the extracts S1, S2 and S3 showed the same MIC50 value of $25.53 \mu \mathrm{g} \cdot \mathrm{ml}^{-1}$ and MIC90 value of $27.14 \mu \mathrm{g} . \mathrm{ml}^{-1}$. The extract S1 and S2 have showed the same activity against Bacillus thuringiensis, Clostridium perfringens and Listeria monocytogenes at MIC50. Our results show that Gram-positive bacteria were more susceptible to the addition of plant extract and this could be confirmed with the previous studies where Bacillus spp. was susceptible to active compounds of plants extracts (Didry et al., 1998; Krolicka et al., 2009). 
The studies on antimicrobial properties of extracts from different species of Drosera are still ongoing and positive antibacterial effect and determination of values MIC was done by Taraszkiewicz et al. (2012), who demonstrated that extracts of Drosera gigantea contain antibacterial compounds that can be used against Pseudomonas syringae. Other author focused on Drosera intermedia extracts and this extract was the most effective against Staphylococcus epidermidis for which a MIC value of $13.0 \mu \mathrm{g} . \mathrm{ml}^{-1}$ was scored (Grevenstuk et al. 2009). Other Drosera was studied by Didry et al. (1998), who revealed that extract from Drosera peltata showed the broad spectrum activity against numerous bacteria of the oral cavity, with greatest activity against Gram-positive bacteria Streptococcus mutans and S. sobrinus with MIC value $31.25 \mu \mathrm{g} . \mathrm{ml}^{-1}$ and $15.63 \mu \mathrm{g} \cdot \mathrm{ml}^{-1}$, respectively.

Plant extracts are a very rich source of secondary metabolites with antibacterial action, and their application provides an opportunity to effectively combat also antibiotic-resistant bacterial strains (Cuhnie, 2005).

Previously Krolicka et al. (2008) demonstrated that extracts obtained from several other in vitro cultured carnivorous plants possess antibacterial activity towards various pathogens in planktonic culture such as Escherichia coli Enterococcus faecalis, Klebsiella pneumoniae and $S$. aureus. The study of Krychowiak et al. (2014) was the first report describing the efficiency of the $D$ binata extract itself in eliminating the dangerous human pathogen $S$ aureus, resulting however in the increased cytotoxicity of extract on human keratinocytes. The antimicrobial effectiveness of the chloroform plant extract was similar towards all studied $S$. aureus strains, regardless of their resistance to antibiotics. However, a higher bactericidal concentration (MBEC $64 \mu \mathrm{g} \cdot \mathrm{ml}^{-1}$ ) was required for in vitro cultured biofilm.

\section{CONCLUSION}

In conclusion, the extracts of the tested Drosera rotundifolia exhibited good potential antibacterial activity and the potential for developing of antimicrobial agents. The active extracts should be evaluated further in-depth to isolate other active components and detect their mode of action. Drosera species represen a promising alternative source of material for medicinal use. Drosera extract in this study show very good antimicrobial activity against Gram-positive bacteria.
Krolicka, A., Szpitter, A., Maciag, M., Biskup, E., Gilgenast, E., Romanik, G., Kaminski, M. \& Wegrzyn, G. (2009). Antibacterial and antioxidant activity of the secondary metabolites from in vitro cultures of the Alice Sundew (Drosera alicie). Biotechnology and Applied Biochemistry, 53(3), 175 184. http://dx.doi.org/10.1111/j. 10.1042/BA20080088.x

Królicka A, Szpitter A, Gilgenast E, Romanik G, Kamiński M, et al. (2008) Stimulation of antibacterial naphthoquinones and flavonoids accumulation in carnivorous plants grown in vitro by addition of elicitors. Enzyme Microbial Technology, 42, 216-221. doi: 10.1016/j.enzmictec.2007.09.011

Krychowiak, M, Grinholc, M, Banasiuk, R, Krauze-Baranowska ,M, Głód, D, Kawiak, A, et al. (2014) Combination of silver nanoparticles and Drosera binata extract as a possible alternative for antibiotic treatment of burn wound infections caused by resistant Staphylococcus aureus. PLoS ONE, 9(12) e115727. doi:10.1371/journal.pone.0115727

Studnička, M. (2006).Masožravérostliny. (vol.1). Praha: Academia.

Šamaj, J. ,Blehová, M., Repčák, M., Ovečka M. \& Bobák, M. (1999). Drosera species (Sundew): In vitro culture and the production of plumbagin and other secondary metabolites. Medicinal and Aromatic Plants, 43(11), 105-136.

Taraszkiewicz, S. Jafra, A. Skrzypczak, M. Kaminski \& Krolicka, A. (2012). Antibacterial activity of secondary metabolites from in vitro culture of Drosera gigantean against the plant pathogenic bacteria Pseudomonas syringae $p v$ syringae and $P$. syringae pv. morsprunorum A. Journal of Plant Pathology, 91(1), 63.http://dx.doi.org/10.4454/jpp.v94i1sup.011

Thoren, M., Tuomi, J., Kämäräinen, T. \& Laine. K. (2003). Resource availability affects investment in carnivory in Drosera rotundifolia. New Phytologist, 159(2), 507-411.http://dx.doi.org/10.1046/j.1469-8137.2003.00816.x

Vásquez - Collantes, S. G., Rojas - Idrogo, C. \& Delgado-Paredes, G. E. (2014) In vitro flowering and plantlets elongation in "Sundew" Drosera capillaris. International Journal of Plant, Animal and Environmental Sciences, 4(3), 508 517.

Zehl, M, Braunberger, C, Conrad, J, Crnogorac, M, Krasteva, S, et al. (2011) Identification and quantification of flavonoids and ellagic acid derivatives in therapeutically important Drosera species by LC-DAD, LC-NMR, NMR and LC-MS. Analytical and Bioanalytical Chemistry, 400, 2565-2576 10.1007/s00216-011-4690-3

Acknowledgments: This work was supported by grant VEGA 1/0611/14.

\section{REFERENCES}

Andrews, J. M. (2001). Determination of minimum inhibitory concentrations. Journal of Antimicrobial Chemotheraphy, 48(1), 516. http://dx.doi.org/10.1093/jac/dkf083

Banasiuk, R., Kawiak, A. \& Królicka, A. (2012). In vitro cultures of carnivorous plants from the Drosera and Dionaea genus for the production of biologically active secondary metabolites. Journal of Biotechnology, Computational Biology and Bionanotechnology, 93(2), 87-96.http://dx.doi.org/10.5114/bta.2012.46572

Bobák, M., Blehová, A., Krištín, J., Ovečka, M. \& Šamaj, J. 1995. Direct plant regeneration from leaf explants of Drosera rotundifolia cultured in vitro. Plant Cell Tissue and Organ Culture, 43(1), 43-49. http://dx.doi.org/10.1007/bf00042670

Clinical and Laboratory Standard Institute. Performance standard for antimicrobial susceptibility testing. Wayne, PA: Clinical and Laboratory Standard Institute; 2009. [Online] Available from: http://www.techstreet.com/products/1760826. [Accessed on 2nd November, 2015].

Cushnie, T. P. \& Lamb, A. J. (2005). Antimicrobial activity of flavonoids.

InternationalJournal of Antimicrobial Agents, 26(5), 343-356.

http://dx.doi.org/10.1016/j.ijantimicag.2005.09.002

Darwin, C. R. (1875). Insectivorous plants. (vol. 1). London: John Murray

Didry, N., Dubreuil, L., Trotin, F. \& Pinkas, M. (1998). Antimicrobial activity of aerial parts of Drosera peltata Smith on oral bacteria. Journal of Ethnopharmacology, 60(1), 91-96. http://dx.doi.org/10.1016/s03788741(97)00129-3

Grevenstuk, T., Goncalves, S. Almeida, S., Coelho, N., Quintas, C. Gasper, M N. \& Romano, A. (2009). Evaluation of the antioxidant and antimicrobial properties of in vitro cultured Drosera intermedia extracts. Natural Product Communications, 4(8), 1063-1068. http://dx.doi.org/10.1055/s-0029-234359 Juniper, B. E., Robins, R. J. \& Joel, D. M. (1989). The carnivorous plants (Vol.1). California: Academic Press.

Jurgens, A., Sciligo A., Witt, T., El-Sayed, A. M. \& Suckling, D.M. (2012) Pollinator-prey conflict in carnivorous plants. Biological Review Cambridge Philosophical Society, 87(3), 602-615. http://dx.doi.org/10.1111/j.1469185x.2011.00213.x

Kačániová, M., Ďurechová, D., Vuković, N., Kántor, A. Petrová, J., Hleba, L. \& Vatl'ák, A. (2014). Antimicrobial activity of Drosera rotundifolia L. Scientific Papers: Animal Science and Biotechnologies, 47(2), 366-369.

Kačániová, M., Petrová, J., Kántor, A., Terentjeva, M. \& Kluz, M. (2015). In vitro antimicrobial activity of four Slovak medicinal plants against differen strains of bacteria. Animal Science and Biotechnologies, 48(1), 137-145. 